\title{
ANALISIS RASIO PROFITABILITAS PADA PT. BANK NEGARA INDONESIA SYARIAH
}

\author{
Yulia Permata Sari, Doni Marlius \\ Akademi Keuangan dan Perbankan Padang \\ Yuliapermatas05@gmail.com
}

\begin{abstract}
This research was conducted to find out how the level of profitability by using the ratio of ROA (Return on Asset), ROE (Return on Equity), BOPO (Operating Expenses to Operating Income), and NPM (Net Profit Margin) to PT. BNI Syariah bank. The type of data used is secondary data obtained by the documentation method taken from the BNI Syariah bank publication report during the period 2013-2017. This research was conducted using the 2013-2017 financial statements, namely the balance sheet and income statement. based on profitability analysis, it can be seen that ROA experienced fluctuations from 2013 to 2017, as seen from the five year ROA which ha decreased in 2017. Then ROE and NPM for five years, the results show an increasing percentage, with the highest percentage in 2017. And BOPO which fluctuated with the highest percentage in 2014 and the lowest in 2016. The result shows that the level of bank profitability is not stable enough and efficient in carrying out the company's operations.
\end{abstract}

Keyword : Return on Asset (ROA), Return on Equity, Net Profit Margin, BOPO, and Profitability

\section{PENDAHULUAN}

Bank merupakan lembaga yang memiliki peran penting dalam pertumbuhan perekonomian suatu Negara, yang berfungsi sebagai wadah untuk melakukan simpan pinjam uang, serta memberikan jasa lainnya. Jasa yang diberikan diantaranya yaitu transfer dana antar rekening, pembayaran tagihan, sarana investasi, dan lain sebagainya. Kegiatan ini didukung dengan perkembangan Teknologi Ekonomi Digital atau yang lebih populer dengan istilah Fintech.

Menurut Undang-Undang RI No. 10. 1998 tentang perubahan UndangUndang No. 7 Tahun 1992, Bank adalah badan usaha yang menghimpun dana dari masyarakat dalam bentuk simpanan dan menyalurkannya ke masyarakat dalam bentuk kredit atau dalam bentuk lainnya dalam rangka meningkatkan taraf hidup rakyat banyak.

Bank di Indonesia terbagi atas Dual Banking System yaitu bank konvensional dan bank syariah. Kehadiran bank syariah atau bank yang berprinsipkan kepada ajaran Islam di Indonesia masih tergolong sangat baru yaitu sekitar tahun 1990-an. Adapun faktor munculnya bank syariah di Indonesia adalah karena kebanyakan penduduknya yang muslim, oleh alasan tersebut muncul kebutuhan akan adanya bank syariah di Indonesia.

Menurut Undang-Undang RI No. 21. 2008 tentang Perbankan Syariah, Perbankan Syariah adalah segala sesuatu yang menyangkut tentang bank syariah dan unit usaha syariah, mencangkup kelembagaan, kegiatan usaha, serta cara dan 
proses dalam melaksanakan kegiatan usahanya. Salah satu BUS yang ada di Indonesia yaitu PT. Bank BNI Syariah.

Bank syariah mampu menunjukkan peranannya dalam memberikan jasa pelayanan terhadap masyarakat dalam bidang financial yang tentunya dengan memperhatikan prinsip ajaran Islam dan perundang-undangan yang berlaku. Agar dapat melaksanakan tugas pokoknya dan menjaga kelangsungan bank syariah, maka bank wajib menjaga kepercayaan masyarakat dan kualitas pelayanannya. Untuk mengetahui bagaimana gambaran perkembagan financial suatu bank, maka perlu dilakukan analisa terhadap data financial dari bank yang berkepentingan dimana data tersebut tercantum di dalam laporan keuangan.

Laporan keuangan merupakan laporan yang mampu menunjukkan perkembangan posisi finansial dan mempunyai arti yang penting bagi perusahaan karena laporan keuangan pada perusahaan dapat mencerminkan kinerja yang telah tercapai pada suatu waktu dan untuk melihat kesanggupan perusahaan dalam menanggulangi masalah keuangan serta menentukan keputusan yang tepat (Zainal and Marlius. 2017). Laporan keuangan juga dapat mengambarkan seberapa besar perolehan profit pada suatu entitas pada kurun waktu tertentu.

Dalam menganalisis dan menilai posisi keuangan serta seberapa jauh kesanggupan bank dalam memperoleh keuntungan atau laba maka diperlukan keefektifan kegiatan operasional atau kinerja bank, yang dapat diketahui dari rasio profitabilitas bank (Fernos. 2017).

Rasio profitabilitas adalah rasio yang digunakan untuk menilai kesanggupan perusahaan dalam mendapatkan profit. Profitabilitas mempunyai arti yang lebih berharga dari pada laba karena profitabilitas menunjukkan ukuran efesiensi kinerja perusahaan yaitu membandingkan laba yang didapat dengan kekayaan atau modal yang dihasilkan laba tersebut (Pramuka, 2010). Semakin tinggi rasio profitabilitas bank maka bank dapat dikatakan memiliki kinerja yang baik dan sebaliknya.

Untuk menganalisa profitabilitas bank kita dapat mengukur dengan menggunakan berbagai rasio keuangan beberapa diantaranya yaitu rasio Return On Asset (ROA), Return On Equity (ROE), Net Profit Margin (NPM), dan Beban Operasional terhadap Pendapatan Operasional (BOPO). NPM adalah rasio yang menunjukkan kesanggupan bank dalam memperoleh laba bersih.

ROA merupakan alat untuk mengetahui besarnya tingkat efektiftas bank di dalam mendatangkan laba atau profit dengan memanfaatkan semua asset yang dimiliki. (Afriyeni, Jhon Fernos. 2018: 329).

ROE yaitu tingkat pemulangan modal bank, yang digunakan untuk mengukur kemampuan bank dengan mengendalikan modal yang dimiliki untuk menghasilkan keuntungan. Sedangkan BOPO digunakan untuk mengetahui tingkat efisiensi dan kesanggupan bank dalam mendatangkan keuntungan dengan memanfaatkan biaya operasionalnya.

PT. Bank BNI Syariah adalah salah satu Bank Umum Syariah (BUS) yang ada di Indonesia yang kegiatannya tidak terlepas dari bidang keuangan yang harus memperhatikan keefektifan operasionalnya dan juga perolehan profitnya dalam pemanfaatan asset dan modal yang dimilikinya dengan memperhatikan aturanaturan perbankan syariah yang berlaku agar perolehan laba tidak menjadi riba 
nantinya. Berikut hasil perkembangan data awal laporan neraca dan laba rugi PT. Bank BNI Syariah untuk periode 2013 hingga 2017.

\section{Tabel 1}

\section{Data Keuangan PT. Bank BNI Syariah} Periode 2013 - 2017

Dalam juta rupiah

\begin{tabular}{|c|c|c|c|c|c|}
\hline \multirow[t]{2}{*}{ Keterangan } & \multicolumn{5}{|c|}{ Tahun } \\
\hline & 2013 & 2014 & 2015 & 2016 & 2017 \\
\hline Total Aset & 14.708 .504 & 19.492 .112 & 23.017 .667 & 28.314 .175 & 34.822 .442 \\
\hline $\begin{array}{l}\text { Modal } \\
\text { Sendiri }\end{array}$ & 1.001 .000 & 4.004 .000 & 4.004 .000 & 4.004 .000 & 4.004 .000 \\
\hline $\begin{array}{l}\text { Pendapatan } \\
\text { operasioal }\end{array}$ & 1.612 .222 & 2.177 .404 & 2.573 .188 & 2.960 .724 & 3.399 .586 \\
\hline $\begin{array}{l}\text { Beban } \\
\text { Operasional }\end{array}$ & 1.420 .506 & 1.955 .500 & 2.306 .347 & 2.572 .265 & 2.978 .807 \\
\hline $\begin{array}{l}\text { Laba } \\
\text { sebelum } \\
\text { pajak }\end{array}$ & 179.616 & 220.130 & 307.768 & 373.197 & 408.747 \\
\hline Laba bersih & 117.462 & 163.251 & 228.525 & 277.375 & 306.686 \\
\hline
\end{tabular}

Sumber: www.bnisyariah.co.id data diolah

Berdasarkan tabel 1 dapat dilihat bahwa data awal neraca dan laporan laba rugi PT. Bank BNI Syariah selalu mengalami kenaikan tiap tahunnya. Ini diketahui dari perolehan pendapatan operasional dari tahun 2013 (Rp. 1.612.222) dan tahun 2014 (Rp. 2.177.404) naik sebesar Rp. 565.182, sedangkan dari tahun 2015 (Rp. 2.573.188) ke tahun 2016 (Rp. 2.960.724) juga terjadi kenaikan sebesar Rp. 387.536, serta pada tahun 2017 pendapatan operasional juga terjadi peningkatan sebasar Rp. 438.862 dari tahun sebelumnya. sedangkan untuk perolehan laba bersih juga mengalami hal yang serupa dengan kenaikan dari tahun 2013 (Rp. 117.642) ke tahun 2014 (Rp. 163.251) sebesar Rp. 45.609, sedangkan tahun 2015 (Rp. 228.525) ke tahun 2016 (Rp. 277.375) naik sebesar Rp. 48.850, serta tahun 2017 (Rp. 306.686) naik sebesar Rp. 29.311 dari tahun sebelumnya.

Berdasarkan uraian di atas maka penulis tertarik untuk melakukan analisis yang hasilnya akan dituangkan dalam laporan tugas akhir yang berjudul "ANALISIS RASIO PROFITABILITAS PADA PT. BANK BNI SYARIAH"

Berdasarkan latar belakang tersebut, adapun rumusan masalah dalam penelitian ini yaitu "Bagaimana tingkat profitabilitas PT. Bank BNI Syariah periode 2013 - 2017?"

Penelitian ini bertujuan untuk mengetahui bagaimana tingkat profitabilitas PT. Bank BNI Syariah periode 2013 - 2017 dengan menggunakan rasio ROA, ROE, BOPO, dan NPM.

\section{METODE PENELITIAN}

Dalam pengumpulan data dan bahan untuk melakukan penelitian ini, penulis menggunakan metode dengan dua cara sebagai berikut : a. Peninjauan Langsung ke Objek yaitu penelitian langsung ke objek penelitian yang dipilih untuk meneliti hasil data primer. Penelitian langsung kelapangan ini akan dapat membantu 
penulis untuk menambahkan data yang diperlukan. Adapun cara riset lapangan ini yaitu dengan cara mewawancarai langsung pihak terkait dalam hal ini adalah perusahaan atau instansi terkait. b. Studi Keperpustakaan (Lebrary Research) yaitu Penelitian ini dilakukan ke perpustakaan berupa buku-buku ilmiah dan tulisan-tulisan yang berhubungan dengan pembahasan yang dilakukan.

\section{HASIL DAN PEMBAHASAN}

1. Analisa Terhadap Return On Asset (ROA)

Menurut Bank Indonesia (SE BI No. 10/46/DInt. 2008) Return on Asset merupakan rasio yang menggambarkan tingkat keuntungan (earning) yang didapatkan oleh manajemen atas total asset yang dimiliki.

Return On Asset adalah rasio yang mencerminkan kesangupan bank dalam mengendalikan dana yang diinvestasikan dalam semua asset yang mendatangkan keuntungan (Kusuma. 2013).

Rasio ini dipakai untuk mengukur kesangupan manajemen bank BNI Syariah dalam mendapatkan keuntungan (laba) secara keseluruhan. Rasio ini juga dapat menggambarkan efesiensi kemampuan kerja bank yang bersangkutan dan juga dapat digunakan untuk mengukur kemampuan bank dalam mengelola seluruh biaya-biaya operasional dan non-operasional. Matriks penilaian tingkat rasio ROA menurut Bank Indonesia adalah sebagai berikut :

Tabel 2

Matriks Kriteria Penilaian Tingkat ROA

\begin{tabular}{lll}
\hline 1 & ROA $>1,5 \%$ & Sangat baik \\
2 & $1,25 \%<\mathrm{ROA} \leq 1,5 \%$ & Baik \\
3 & $0,5 \%<\mathrm{ROA} \leq 1,25 \%$ & Cukup \\
4 & $0 \%<\mathrm{ROA} \leq 0,5 \%$ & Tidak baik \\
5 & $0<\mathrm{ROA} \leq 0,5 \%$ & Sangant tidak baik \\
\hline
\end{tabular}

Sumber: www.bi.go.id

Berdasarkan data yang diperoleh Return On Asset Bank BNI Syariah pada periode 2013 - 2017 ditunjukkan pada tabel dibawah ini.

Tabel 3

Perhitungan Return On Asset Bank BNI Syariah Periode 2013 - 2017

\begin{tabular}{ccc} 
& \multicolumn{2}{c}{ Deturn On Asset juta rupiah } \\
\hline \multirow{2}{*}{ Komponen } & Laba Sebelum Pajak & Total Aktiva \\
\hline 2013 & 179.616 & 14.708 .504 \\
2014 & 220.130 & 19.492 .112 \\
2015 & 307.768 & 23.017 .667 \\
2016 & 373.197 & 28.314 .175 \\
2017 & 408.747 & 34.822 .442 \\
\hline
\end{tabular}

Sumber: Data olahan 
Dengan Formula :

$$
\mathrm{ROA}=\frac{\text { Laba Sebelum Pajak }}{\text { Total Asset }} \times 100 \%
$$

1. Desember 2013

2. Desember 2014

$$
\mathrm{ROA}=\frac{R p \cdot 179 \cdot 616}{R p \cdot 14.708 .504} \times 100 \%=1,22 \%
$$

$$
\mathrm{ROA}=\frac{R P .220 .130}{R p \cdot 19.492 .112} \times 100 \%=1,13 \%
$$

3. Desember 2015

4. Desember 2016

$$
\mathrm{ROA}=\frac{R p \cdot 307.768}{R p \cdot 23.017 .667} \times 100 \%=1,34 \%
$$

$$
\mathrm{ROA}=\frac{R p \cdot 373 \cdot 197}{R p \cdot 28 \cdot 314 \cdot 175} \times 100 \%=1,32 \%
$$

5. Desember 2017

$$
\mathrm{ROA}=\frac{R p .408 .747}{R p .34 .822 .442} \times 100 \%=1,17 \%
$$

ROA Bank BNI Syariah tahun 2013 sebesar 1,22\%, tahun 2014 sebesar 1,13\%, tahun 2015 sebesar 1,34\%, tahun 2016 sebesar 1,32\%, dan tahun 2017 sebesar $1,17 \%$. Berdasarkan perhitungan tersebut dapt disimpulkan ROA Bank BNI Syariah masih berfluktuasi. Walaupun demikian perkembagan profitabilitas bank BNI Syariah masih cukup baik dan dapat dikatakan efesien. Namun apabila ROA semakin rendah bank tidak akan bisa beroperasi dengan efektif dan efesien dalam memanfaatkan asset yang dimiliki oleh bank untuk menghasilkan keuntungan.

2. Analisa Terhadap Return On Equity

Menurut (SE BI No. 10/46/DInt. 2008) Return On Equity (ROE) merupakan rasio yang menyatakan tingkat pengembalian (return) yang didapatkan oleh manajemen atas modal yang ditanam oleh pemegang saham.

Return On Equity (ROE) merupakan rasio yang dipakai untuk mengukur kemampuan manajemen bank dalam memanfaaatkan modal yang tersedia (ekuitas) untuk mendatangkan laba setelah pajak (Kusuma. 2013). Rasio ini menerangkan daya untuk mendapatkan laba atas investasi berdasarkan nilai buku para pemegang saham. Semakin tinggi rasio ini, semakin baik, demikian pula sebaliknya. ROE yang tinggi akan dapat mendorong penerimaan bank atas peluang investasi yang baik dan manajemen biaya yang efektif. Hal ini dapat mempengaruhi minat investor untuk melakukan transaksi jual beli saham, sehingga akan meningkatkan volume penjualan saham perusahaan tersebut.

Matriks penilaian tingkat rasio ROE menurut Bank Indonesia adalah sebagai berikut (Surat Edaran BI No. 13/24/DPNP 2011) : 
Tabel 4

Matriks Kriteria Penilaian Tingkat ROE

\begin{tabular}{lll}
\hline 1 & ROE $>23 \%$ & Sangat baik \\
2 & $18 \%<\mathrm{ROE} \leq 23 \%$ & Baik \\
3 & $13 \%<\mathrm{ROE} \leq 18 \%$ & Cukup \\
4 & $8 \%<\mathrm{ROE} \leq 13 \%$ & Kurang baik \\
5 & $\mathrm{ROE} \leq 8 \%$ & Sangat tidak baik \\
\hline
\end{tabular}

Sumber: www.bi.go.id

Berdasarkan data yang diperoleh Return On Equity Bank BNI Syariah pada periode 2013 - 2017 ditunjukkan pada tabel dibawah ini.

Tabel 5

Perhitungan Return On Equity PT. Bank BNI Syariah

Periode 2013 - 2017

Dalam juta rupiah

\begin{tabular}{ccc}
\hline \multirow{2}{*}{ Komponen } & \multicolumn{2}{c}{ Return On Equity } \\
& Laba Setelah Pajak & Modal Sendiri \\
\hline 2013 & 117.462 & 1.001 .000 \\
2014 & 163.251 & 4.004 .000 \\
2015 & 228.525 & 4.004 .000 \\
2016 & 277.375 & 4.004 .000 \\
2017 & 306.686 & 4.004 .000 \\
\hline
\end{tabular}

Sumber : Data olahan

Dengan Formula :

$$
\mathrm{ROE}=\frac{\text { Laba Bersih }}{\text { Modal Sendiri }} \times 100 \%
$$

1. Desember 2013

$$
\mathrm{ROE}=\frac{R p \cdot 117.462}{R p \cdot 1.001 .000} \times 100 \%=11,73 \%
$$

2. Desember 2014

$$
\mathrm{ROE}=\frac{R p \cdot 163 \cdot 251}{R p \cdot 4 \cdot 004 \cdot 000} \times 100 \%=4,08 \%
$$

3. Desember 2015

$$
\mathrm{ROE}=\frac{R p .228 .525}{R p .4 .004 .000} \times 100 \%=5,71 \%
$$

4. Desember 2016

$$
\mathrm{ROE}=\frac{R P \cdot 277.375}{R p \cdot 4 \cdot 004.000} \times 100 \%=6,93 \%
$$

5. Desember 2017

$$
\mathrm{ROE}=\frac{R p \cdot 306.686}{R p .4 .004 .000} \times 100 \%=7,66 \%
$$

ROE Bank BNI Syariah tahun 2013 sebesar 11,73\%, tahun 2014 sebesar 4,08\%, tahun 2015 sebesar 5,71\%, tahun 2016 sebesar 6,93\%, dan tahun 2017 sebesar 7,66\%. Berdasarkan perhitungan tersebut ROE Bank BNI Syariah mengalami penurun pada tahun 2014. Namun pada tahun berikutnya ROE Bank BNI Syariah terus mengalami peningkatan. Walaupun dengan persentase yang cukup rendah, bank masih cukup efektif dan efesien dalam memanfaatkan modal yang dimilikinya untuk memperoleh keuntungan. 
3. Analisa Beban Operasional Terhadap Pendapatan Operasional

Rasio beban operasional diguanakan untuk mengukur ringkat efisiensi dan kemampuan bank dalam melakukan kegiatan operasionalnya. Rasio BOPO sering disebut rasio efisiensi digunakan untuk mengukur kemampuan manajemen bank dalam mengendalikan biaya operasional terhadap pendapatan operasional. Matriks penilaian tingkat rasio BOPO menurut Bank Indonesia adalah sebagai berikut (Surat Edaran BI No. 13/24/DPNP 2011) :

\section{Tabel 6}

Matriks Kriteria Penilaian Tingkat BOPO

\begin{tabular}{lll}
\hline 1 & BOPO $\leq 83 \%$ & Sangat baik \\
2 & $83 \%<$ BOPO $\leq 85 \%$ & Baik \\
3 & $85 \%<$ BOPO $\leq 87 \%$ & Cukup \\
4 & $87 \%<$ BOPO $\leq 89 \%$ & Tidak Baik \\
5 & BOPO $\geq 89 \%$ & Sangat tidak baik \\
\hline Sumber $:$ www.bi.go.id &
\end{tabular}

Berdasarkan data yang diperoleh Beban Operasional terhadap Pendapatan Operasional Bank (BOPO) BNI Syariah pada periode 2013 2017 ditunjukkan pada tabel dibawah ini.

\section{Tabel 7}

Perhitungan Biaya Operasional Terhadap Pendapatan Operasional PT. Bank BNI Syariah

Periode 2013 - 2017

\begin{tabular}{lcc} 
& \multicolumn{2}{c}{ Dalam juta rupiah } \\
\hline \multirow{2}{*}{ Komponen } & $\begin{array}{c}\text { Total } \\
\end{array}$ & BOPO \\
& Pendapatan Operasional & Total \\
2013 & 1.612 .222 & Beban Operasional \\
2014 & 2.177 .404 & 1.420 .506 \\
2015 & 2.573 .188 & 1.955 .500 \\
2016 & 2.960 .724 & 2.306 .347 \\
2017 & 3.399 .586 & 2.572 .265 \\
\hline
\end{tabular}

Sumber : Data olahan

Dengan Formula :

$$
\mathrm{BOPO}=\frac{\text { Total Biaya Operasional }}{\text { Total Pendapatan Operasional }} \times 100 \%
$$

1. Desember 2013

$$
\mathrm{BOPO}=\frac{R P \cdot 1 \cdot 420.506}{R p \cdot 1 \cdot 612.222} \times 100 \%=88,10 \%
$$

2. Desember 2014

$$
\mathrm{BOPO}=\frac{R P \cdot 1 \cdot 955.500}{R p \cdot 2 \cdot 177.404} \times 100 \%=89,8 \%
$$

3. Desember 2015

$$
\mathrm{BOPO}=\frac{R P \cdot 2 \cdot 306.347}{R p \cdot 2 \cdot 573 \cdot 188} \times 100 \%=89,6 \%
$$


4. Desember 2016

$$
\mathrm{BOPO}=\frac{R P \cdot 2 \cdot 572.265}{R p \cdot 2 \cdot 960.724} \times 100 \%=86,87 \%
$$

5. Desember 2017

$$
\mathrm{BOPO}=\frac{R P .2 .978 .807}{R p \cdot 3.399 .586} \times 100 \%=87,62 \%
$$

BOPO Bank BNI Syariah tahun 2013 sebesar 88,10\%, tahun 2014 sebesar 89,8\%, tahun 2015 sebesar 89,6\%, tahun 2016 sebesar 86.87\%, dan tahun 2017 sebesar 87,63\%. Dari hasil tersebut dapat ditarik kesimpulan bahwa kinerja Bank BNI Syariah masih belum cukup efesien walaupun persentase BOPO masih tergolong kedalam rata-rata penilaian BI. Semakin kecil BOPO semakin efesien bank tersebut dalam mengendalikan biaya operasionalnya, maka keuntungan yang diperoleh bank akan maksimal.

4. Analisa Terhadap Net Profit Margin

Menurut Bank Indonesia (SE BI No. 10/46/DInt. 2008) Net Profit Margin merupakan rasio yang memperlihatkan kontribusi penjualan terhadap laba bersih yang dihasilkan.

Rasio ini mengukur sejauh mana kemampuan bank BNI Syariah dalam mendatangkan laba bersih pada tingkat penjualan/ pendapatan tertentu. Rasio ini bisa diinterprestasikan juga sebagai kemampuan bank menekan biayabiaya perusahaan pada periode tertentu. Matriks penilaian tingkat rasio NPM menurut Bank Indonesia adalah sebagai berikut (Surat Edaran BI No. 6/23/DPNP 2004) :

\section{Tabel 8}

Matriks Kriteria Penilaian Tingkat NPM

\begin{tabular}{lll}
\hline 1 & $\mathrm{NPM} \geq 100 \%$ & Sangat baik \\
2 & $81 \% \leq \mathrm{NPM}<100 \%$ & Baik \\
3 & $66 \% \leq \mathrm{NPM}<81 \%$ & Cukup \\
4 & $51 \% \leq \mathrm{NPM}<66 \%$ & Tidak baik \\
5 & $\mathrm{NPM}<51 \%$ & Sangat tidak baik \\
\hline
\end{tabular}

Sumber: www.bi.go.id

Berdasarkan data yang diperoleh Net Profit Margin BNI Syariah pada periode 2013 - 2017 ditunjukkan pada tabel dibawah ini.

Tabel 9

Perhitungan Net Profit Margin PT. Bank BNI Syariah Periode 2013 - 2017

Dalam juta rupiah

\begin{tabular}{ccc}
\hline \multirow{2}{*}{ Komponen } & \multicolumn{2}{c}{ Net Profit Margin } \\
& Laba Setelah Pajak & Total Pendapatan Operasional \\
\hline 2013 & 117.462 & 1.612 .222 \\
2014 & 163.251 & 2.177 .404 \\
2015 & 228.525 & 2.573 .188 \\
2016 & 277.375 & 2.960 .724 \\
2017 & 306.686 & 3.399 .586 \\
\hline
\end{tabular}

Sumber : Data olahan 
Dengan Formula :

$$
\mathrm{NPM}=\frac{\text { Laba Setelah Pajak }}{\text { Total Pendapatan }} \times 100 \%
$$

1. Desember 2013

$$
\mathrm{NPM}=\frac{R p \cdot 117 \cdot 462}{R p \cdot 1 \cdot 612 \cdot 222} \times 100 \%=7,28 \%
$$

2. Desember 2014

$$
\mathrm{NPM}=\frac{R p \cdot 163 \cdot 251}{R p \cdot 2 \cdot 177 \cdot 404} \times 100 \%=7,5 \%
$$

3. Desember 2015

$$
\mathrm{NPM}=\frac{R p .228 .525}{R p \cdot 2.573 .188} \times 100 \%=8,8 \%
$$

4. Desember 2016

$$
\mathrm{NPM}=\frac{R p \cdot 277 \cdot 375}{R p \cdot 2 \cdot 960 \cdot 724} \times 100 \%=9,37 \%
$$

5. Desember 2017

$$
\mathrm{NPM}=\frac{R p \cdot 306.686}{R p .3 .399 .586} \times 100 \%=9,02 \%
$$

NPM Bank BNI Syariah tahun 2013 sebessar 7,28\%, tahun 2014 sebesar 7,5\%, tahun 2015 sebesar 8,8\%, tahun 2016 sebesar 9,37\%, dan tahun 2017 sebesar 9,02\%. Berdasarkan perhitungan tersebut NPM Bank BNI Syariah selalu mengalami kenaikan, berarti kemampuan bank dalam memperoleh laba dengan pengelolaan biaya operasional bank juga semakin efektif. Jika rasio ini semakin besar maka akan semakin baik.

\section{SIMPULAN}

Gambaran tingkat profitabilitas PT. Bank BNI Syariah selama periode 2013 hingga 2017 disimpulkan bahwa :

\section{Table 10}

Perbandingan Rasio Profitabilitas

PT. Bank BNI Syariah

Periode 2013 - 2017

\begin{tabular}{ccccccc}
\hline Rasio & $\mathbf{2 0 1 3}$ & $\mathbf{2 0 1 4}$ & $\mathbf{2 0 1 5}$ & $\mathbf{2 0 1 6}$ & $\mathbf{2 0 1 7}$ & Rata Industri \\
\hline ROA & $1,22 \%$ & $1,13 \%$ & $1,34 \%$ & $1,32 \%$ & $1,17 \%$ & $0,5 \%$ \\
ROE & $11,73 \%$ & $4,08 \%$ & $5,71 \%$ & $6,93 \%$ & $7,66 \%$ & $5 \%$ \\
BOPO & $88,10 \%$ & $89,8 \%$ & $89,6 \%$ & $86,87 \%$ & $87,62 \%$ & $100 \%$ \\
NPM & $7,28 \%$ & $7,5 \%$ & $8,8 \%$ & $9,37 \%$ & $9,02 \%$ & $10 \%$ \\
\hline
\end{tabular}

1. Dari rasio ROA PT. Bank BNI Syariah tahun 2013 nilainya sebesar 1,22\%, tahun 2014 ROA nilainya sebesar 1,13\%, tahun 2015 ROA nilainya sebesar $1,34 \%$, tahun 2016 ROA nilainya sebesar 1,32\%, dan tahun 2017 ROA nilainya sebesar $1,17 \%$. Jadi ROA PT. Bank BNI Syariah masih berfluktuasi. Walaupun demikian perkembagan profitabilitas bank BNI Syariah masih cukup baik dan dapat dikatakan efesien. Namun apabila ROA semakin rendah bank tidak akan bisa beroperasi dengan efektif dan efesien dalam 
memanfaatkan asset yang dimiliki oleh bank untuk menghasilkan keuntungan.

2. Dari rasio ROE PT. Bank BNI Syariah tahun 2013 nilainya sebesar 11,73\%, tahun 2014 ROE nilainya sebesar 4,08\%, tahun 2015 ROE nilainya sebesar $5,71 \%$, tahun 2016 ROE nilainya sebesar 6,93\%, dan tahun 2017 ROE nilainya sebesar $7,66 \%$. Jadi ROE PT. Bank BNI Syariah belum cukup efektif karena pada tahun 2014 terjadi penurunan yang cukup besar dari tahun sebelumnya. Namun pada tahun berikutnya ROE Bank BNI Syariah terus mengalami peningkatan. Walaupun dengan persentase yang cukup rendah dan bank cukup efektif dan efesien dalam memanfaatkan modal yang dimilikinya untuk memperoleh keuntungan.

3. Dari rasio BOPO PT. Bank BNI Syariah tahun 2013 nilainya sebesar $88,10 \%$, tahun 2014 BOPO nilainya sebesar $89,8 \%$, tahun 2015 BOPO nilainya sebesar $89,6 \%$, tahun 2016 BOPO nilainya sebesar $86,87 \%$, tahun 2017 BOPO nilainya sebesar 87,62\%. Semakin kecil BOPO semakin efesien bank tersebut dalam mengendalikan biaya operasionalnya, maka keuntungan yang diperoleh bank akan maksimal.

4. Dari rasio NPM PT. Bank BNI Syariah tahun 2013 nilainya sebesar 7,28\%, tahun 2014 NPM nilainya sebesar 7,5\%, tahun 2015 NPM nilainya sebesar $8,8 \%$, tahun 2016 NPM nilainya sebesar 9,37\%, tahun 2017 NPM nilainya sebesar 9,02\%. Pada tiap tahunnya NPM Bank BNI Syariah selalu mengalami kenaikan, berarti kemampuan bank dalam memperoleh laba dengan pengelolaan biaya operasional bank juga semakin efektif. Jika rasio ini semakin besar maka akan semakin baik, tetapi hal ini dapat dijadikan ukuran yang representatif, karena laba yang diperoleh tersebut juga harus dibandingkan dengan besarnya jumlah dana yang digunakan untuk memperoleh laba tersebut.

\section{DAFTAR PUSTAKA}

Afriyeni, and Fernos Jhon. Analisis Faktor-Faktor Penentu Kinerja Profitabilitas Bank Perkreditan Rakyat (BPR) Konvensional di Sumatera Barat. Jurnal Benefita 3(3), vol. 3, no. September, 2018, pp. 325-35, doi:10.22216/jbe.v3i3.3623 Kopertis.

Arifin, I. Z., \& Marlius, D. (2017). Analisis Kinerja Keuangan PT. Pegadaian Cabang Ulak Karang. https://doi.org/10.31227/osf.io/n2peu

Fernos, Jhon. Analisis Rasio Profitabilitas Untuk Mengukur Kinerja Pt. Bank Pembangunan Daerah Sumatera Barat. Jurnal Pundi, vol. 01, no. 2, 2017, pp. 283-91.

Handayani, M., \& Marlius, D. (2017). Analisis Tingkat Kesehatan PT. BPR Batang Kapas. https://doi.org/10.31227/osf.io/bq48z

Kusuma, Arta. Analisis Rasio Profitabilitas Sebagai Alat Ukur Kinerja PT. Bank BNI Syariah. Jurnal Ilmiah Mahasiswa, vol. 2, no. 1, 2013, Return On 
Asset, Return On Equity Gross Profit Margin ,Net Profit Margin.

Putri, Y. A., \& Marlius, D. (2018). Analisis Tingkat Kesehatan Bank Pada PT. Bank Perkreditan Rakyat (BPR) Jorong Kampuang Tangah Pariaman Cabang Padang. https://doi.org/10.31227/osf.io/r98pv

Pramuka, Bambang Agus. Faktor-Faktor yang Berpengaruh Terhadap Tingkat Profitabilitas Bank Umum Syariah. Jurnal Akuntansi, Manajemen Bisnis Dan Sektor Publik (JAMBSP), vol. 7, no. No. 1, 2010, pp. 63-79.

Rahmayeli, D. S., \& Marlius, D. (2017). Analisis Kinerja Keuangan Pada PT. Bank Perkreditan Rakyat (BPR) Batang Kapas Pesisir Selatan. https://doi.org/10.31227/osf.io/sz5db

Republik Indonesia. 1998. Undang-Undang No. 10/1998 tentang Perubahan UU No. 7/1992 tentang Perbankan.

Republik Indonesia. 2008. Undang-Undang No. 21/2008 tentang Perbankan Syariah.

Surat Edaran Bank Indonesia No. 6/23/DPNP/2004.

Surat Edaran Bank Indonesia No. 10/46/DInt/2008.

Surat Edaran Bank Indonesia No. 13/24/DPNP/2011.

Zainal, Ivo, and Doni Marlius. Analisis Kinerja Keuangan PT . Pegadaian Cabang Ulak Karang. Osf.io, vol. 2, 2017, pp. 1-10. 